\title{
Ascertaining the Paradigm of Secondary Metabolism Enhancement through Gene Level Modification in Therapeutic Plants
}

\author{
Swati Sinha' , Kajal Sandhu', Neema Bisht ${ }^{1}$, Tapan Naliwal', Ishan Saini² and Prashant Kaushik ${ }^{3 *}$ \\ 'Department of Biotechnology, Kumaun University, Bhimtal Campus, Bhimtal, INDIA \\ 2Department of Botany, Kurukshetra University, Kurukshetra, INDIA \\ ${ }^{3}$ Instituto de Conservación y Mejora de la Agrodiversidad Valenciana, Universitat Politècnica de València, Valencia, SPAIN.
}

\begin{abstract}
Since ages plants with therapeutic effects are used for curing several human ailments. With the development in modern biotechnological tools, these therapeutic compounds could be overexpressed in the plants. This review aims to compile the valuable information from the examples in the literature, regarding the biotechnological tools those could be useful for the overproduction of health-promoting biochemicals in the medicinal plants. Gene level modification is all about creating improved variety of plants that are highly resistant to pests and pesticides or contain higher levels of nutrients than conventional plants. Plant secondary metabolites constitute an exciting and vital aspect of research, due to their chemical diversity, varied biological functions and pharmacological activities. Gene modification, through Agrobacterium mediated trans-
\end{abstract}

formation, RNA interference or CRISPER/Cas9, has opened avenues of improvement in medicinal plants and provide an alternative production system of pharmaceutically important secondary metabolites for their commercial exploitation.

Key words: Gene modification, Agrobacterium, RNA interference, CRISPR/Cas9, Medicinal plants.

Correspondence

Dr. Prashant Kaushik

Instituto de Conservación y Mejora de la Agrodiversidad Valenciana, Universitat Politècnica de València-46022, Valencia, SPAIN.

Email: prakau@doctor.upv.es

DOI: 10.5530/jyp.2019.11.70

\section{INTRODUCTION}

Plants synthesize innumerable small phytomolecules, known metabolites via integrated complex interconnected enzyme-mediated biosynthetic pathway. ${ }^{1}$ Plants primarily synthesize two types of metabolites: The primary metabolites, which are vital for the survival of the organisms and any change in their synthesis, can lead to harmful manifestation. ${ }^{2}$ However, secondary metabolites confer a multitude of adaptive and evolutionary advantages to the plants by performing specialized functions and playing a role in providing quality of life to the producer [Figure 1]. Often, secondary metabolites are associated with defense related, antifeedent, insect attractant and repellent functions. ${ }^{3,4}$ Plants are the richest source for the secondary metabolites, which have medicinal and aromatic properties. According to some estimates, approximately 100,000 such secondary metabolites are known to occur in about 50,000 plant species and more than 4,000 unique metabolic compounds are being found each year from several plant species. ${ }^{5-8}$

For thousands of years, we have been dependent on natural plant products for human healthcare in the form of drugs, antioxidants, flavors, fragrances, dyes, insecticides and pheromones., ${ }^{910}$ The global plant-derived product market is expected to gain momentum over the coming years. ${ }^{11}$ Firstly, due to the low cost of herbal medicines compared to allopathy and secondly, due to fewer side effects and no overdose toxicity, that are so common in the case of synthetic drugs. There is an increasing inclination of consumers towards traditional medicines. Consequently, global herbal medicine (Ayurveda, Unani and Traditional Chinese Medicine) market size which was valued at USD 71.19 billion in 2016, is expected to reach $\$ 111$ billion by the end of 2023 . This growth in market, is due to increasing demand and can only be met through intensive research investments and funding, which will support constant supply of these herbal products in near future. ${ }^{12}$

Despite such a substantial increase in demand for nutraceuticals, the associated growth in medicinal crop cultivation has marginally increased. The reasons may be identified as (1) low concentration of targeted phytomolecules in specific plant tissues, (2) technological neglect in growing medicinal crops, (3) conversion of habitats of medicinal plants to food or cash crop cultivation, (4) conventional breeding techniques do not provide desirable level of improvement due to sterility, long generation time and complex biosynthetic pathways involved. ${ }^{13,14}$ In this review, we have compiled the useful information after extensive literature survey concerning the biotechnological tools and those could be useful for the overproduction of health-promoting biochemicals in the medicinal plants.

\section{GENE LEVEL MODIFICATION THROUGH METABOLIC ENGINEERING}

To increase the production of (a group of) compound(s), directed and user manipulation of metabolic pathways at gene level in a living system can be performed by manipulating transporters along with enzymatic and regulatory functions of the cell ${ }^{15,16}$ and eggplant fruits are of different shape and sizes that render them as an ideal system for metabolic engineering. Here, we have developed an agroinfiltration protocol for the transient expression of a gene in the eggplant fruit using GUS bearing; pCAMBIA1304 vector. Thereafter, to prove the effectiveness of the developed protocol, we have used the eggplant hydroxycinnamoyl CoA-quinate transferase (SmHQT Metabolic engineering is now used to improve medicinal plants to meet the requirements of increased human creations are licensed under the identical terms. 


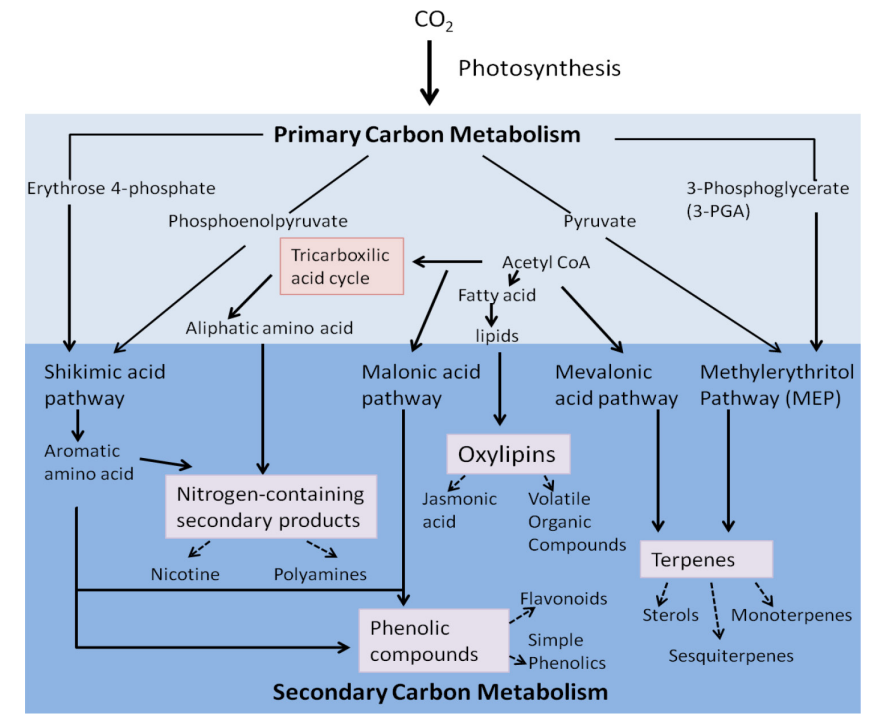

Figure 1: Primary and Secondary Metabolism in Plants.

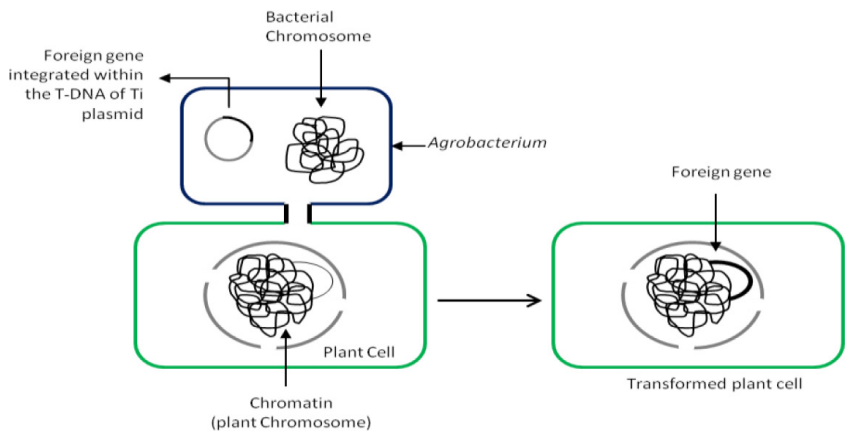

Figure 2: Agrobacterium mediated transformation in plant cells.

health. ${ }^{17}$ Metabolic engineering may be approached through, overexpression or upregulation of gene(s) specific to rate-limiting steps in the pathway and by blocking competitive pathways to reduce degradation of the product of interest. ${ }^{18}$ There have been efforts to alter the expression of some regulatory genes that control multiple genes in the biosynthetic pathway, like down regulation of zeaxanthin epoxidase gene by antisense and co-suppression inhibition, which resulted in an accumulation of zeaxanthin. ${ }^{19}$ By means of metabolic engineering, selective novel metabolites can be produced, the target of secondary metabolite can be overproduced and proportion of toxic and unwanted chemicals can be reduced. The strategy to amplify the metabolic flux of a pathway can be achieved by increasing the composition of the enzyme involved in the rate-limiting step of the pathway. ${ }^{20}$

With progress in tissue culture techniques, combined with development in genetic engineering and bioinformatics, have opened a panorama for large-scale and improved production of secondary metabolites with pharmaceutical and nutritional value. ${ }^{21}$

\section{STRATEGIES TO INDUCE GENE LEVEL MODIFICATION}

Various genetic manipulation techniques and technologies have been applied in plants, such as overexpression of transgenes, expressions of multiple transgenes, gene silencing and overproduction of bioactive plant natural products. ${ }^{22,23}$ To mention a few, three most commonly used methods are discussed below:

\section{AGROBACTERIUM MEDIATED TRANSFORMATION}

For transferring useful genes into crop plants, Agrobacterium-mediated gene transfer is the most frequently used method of transformation, either in differentiated plant cells or into undifferentiated cells of callus [Figure 2]. This method uses the natural ability of Agrobacterium to infect and transfer genes to the plant cells. The success of this method relies on many factors, like type of target cells or tissues and its competence for regeneration and transformation, efficiency of DNA delivery, stringency of system used for selection of transformed cells and the ability to recover fertile transgenic plants. ${ }^{24]}$

Agrobacterium tumefaciens mediated transformation systems in medicinal crops is pertinent to highly efficient and rapid transgenic plant production for desirable traits for cultivation. Increased yield, biotic and abiotic stress tolerance, hyper-production of one or more desirable secondary metabolite or other phytochemicals, suppression of synthesis of one or more undesirable phytochemical, suppression of one or more native genes, metabolic engineering of endogenous pathways, incorporation of genetic traits (genes) of new or non-native metabolic pathways in the plant etc., ${ }^{25,26} \mathrm{~A}$. rhizogenes-based transformation is another potential system for manipulation in biosynthesis of secondary metabolites, mainly in roots of medicinal plants. Ri transformed hairy root cultures shows rapid growth, reduced apical dominance, high branching and increased large scale production of targeted secondary metabolites. ${ }^{27}$

\section{RNA INTERFERENCE}

Out of many possible ways of gene modification, RNAi approach can be used, in which accumulation of preceding intermediates can be enhanced by degrading the mRNA expression of the subsequent gene(s) in that particular pathway. RNA interference is a powerful tool to comprehend gene function in both plants and animals. Gene silencing is considered as suppression of the expression of a gene at either transcription or translation level..$^{28}$

In this approach, particular mRNA is degraded, which is associated with double-stranded DNA. This type of gene silencing is considered as cosuppression or posttranscriptional gene silencing in plants. ${ }^{29,30}$ Although RNA interference is a potent tool in gene silencing, still it has not been exploited much for manipulating plant secondary metabolite production. ${ }^{31}$ Using this method the production of pharmaceutically important secondary metabolites in plants, for instance; Papaver somniferum, $P$. ginseng, A. annua and W. somnifera. ${ }^{32,33}$ Using this method researchers have developed a process for production of non-narcotic alkaloid, reticuline in opium poppy, which is more potent than morphine. Here gene encoding Codeinone Reductase (COR), a key enzyme of morphine biosynthetic pathway was silenced. Increased level of reticuline was observed through feedback mechanism. ${ }^{34}$ This technique has proved to be a breakthrough in molecular biology research and has led to establishment of RNAi focused biotechnology companies. This method of gene silencing is quite simple and is a potent tool for large scale functional analysis in various organisms. ${ }^{35}$

RNA interference is a multistep process that includes enzymes like Drosha, DICER and RISC. Long dsRNA and hairpin molecules occur naturally inside cells and from here the mechanism of RNAi initiates. All dsRNAs and hairpin RNAs are processed with the help of an RNase IIIlike enzyme DICER into 21 to 25 nucleotides duplex. Small siRNAs and miRNAs join with a multi-nuclease complex RISC (RNA induced silencing complex) leading to degradation of homologous mRNAs. ${ }^{36}$ ATP is required for the formation of RISC on siRNA, but once it is established, it can mediate robust cleavage even in absence of ATP. One strand of siRNA is integrated into RISC complex, it is considered as guide strand 


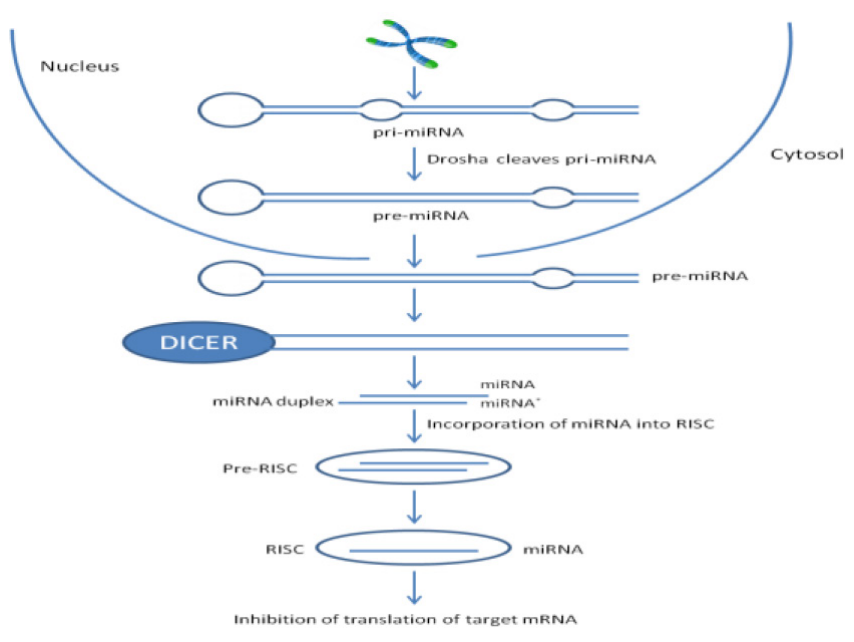

Figure 3: Translational silencing by miRNA.

and the complementary strand is known as passenger strand, degraded as a RISC complex substrate in the process. RISC has a catalytic component called as AGO protein that helps to silent target mRNA. ${ }^{37}$ Most importantly, it is the 5' end of guide strand that acts as a ruler for cleavage of RNA target. RISC complex with guide RNA is targeted to target mRNA, where mRNA is either silenced by forming a double-stranded duplex or degraded by RISC complex as shown in Figure 3.

\section{CRISPR/CAS9}

Some specific bacteria and archaea employ, proteins associated with CRISPR (clustered regularly interspaced short palindromic repeats), to act as an element of their pathogen defence system. ${ }^{38}$ The host cell incorporates the fragments of the pathogen's DNA into its CRISPR loci, hence, attains resistance to a pathogenic organism, subsequently transcribed as CRISPR RNA (crRNA) and guides the degradation of pathogen transcripts. ${ }^{39}$ The non-specific Cas9 nuclease and a single guide RNA present in the CRISPR/Cas9 tool directs Cas9 to the target gene loci and then craft double-strand breaks [Figure 4]. The consequent repair process creates insertion or deletion mutations. ${ }^{40}$ Consequently the plant's native genomic repertoire can be effectively harnessed by employing precise alteration in DNA sequences. The foremost concern is the off-target cleavage by Cas9, this is evaded by selecting exclusive target site, using various tools available like CRISPR-Plant, GT-scan, CRISPR direct, Benchling, Cas-OFFinder, etc. ${ }^{41-45}$

For identifying specific rate-limiting enzyme responsible for metabolic flux in a biosynthetic pathway, RNAi proves to be an efficient and valuable approach, but non-specific gene silencing can occur at a high rate due to sequence homology. This can lead to degradation of non-target transcripts. Using the CRISPR/Cas9 system as a gene knock-out technology, it becomes less likely to experience non-specific targeting since, the small sequences are uniquely designed which are not more that 20-50 bp length. ${ }^{46}$ The advantage of using metabolic engineering techniques like RNA interference or CRISPR/Cas vectors is that they induce site-specific mutations without the requirement of foreign DNA. In view of the fact that no transgene is used to modify plants, they are not included in the category of GMO, thereby easing out the process of biosafety concerns. ${ }^{47}$ Examples from the literature related metabolic engineering are provided in Table 1.

\section{USE OF BIOINFORMATICS}

Integration of system biology knowledge with traditional genetic engineering technique helps by cutting redundant exercise at the wet lab
Cas9 (Inactive)

Guiding RNA (gRNA) with

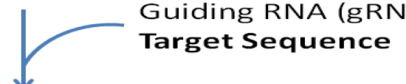

Cas9/gRNA Complex (Active)

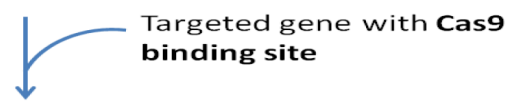

Cutting Mechanism Activated

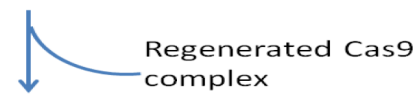

'Broken' genomic DNA

Donor gene

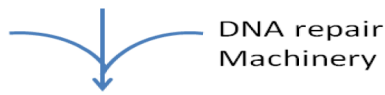

Original Genome with inserted Mutation

Figure 4: General mechanism of CRISPR/Cas9 gene modification.

level. By using bioinformatics tools, we can easily refine our targets (genes/enzymes) for application in metabolic engineering process. ${ }^{72} \mathrm{Bio}-$ informatics tools can be applied to evaluate various proteins involved in secondary metabolism pathways as explained in Figure 5. The secondary structure prediction can help us by elucidating the random coils which are the main components of the protein structure. Further, the model hence developed will serve as a valuable theoretical information which, can provide the physicochemical and structural data in order to functionally assess the target protein. Moreover, biotechnological studies can use the obtained results to manipulate the biosynthesis pathways, for higher secondary metabolite production..$^{73,74}$

\section{SCIENTIFIC CHALLENGES AND ISSUES TO BE ADDRESSED}

To verify the predicted agronomic traits, the ecological relevance of lab trials should be tested under field conditions. It has been observed that genetically modified plants in field trial experience a large number of factors that can influence their predicted performance like, increased pathogen pressure, weather variance and the difference in soil characteristics; which otherwise is not faced by these plants under laboratory conditions. ${ }^{75}$ One such instance goes with transgenic pea plant, which was not able to efficiently express antifungal proteins against Fusarium spp. Additionally, variation in expression of gene was found in different parts of the plant. ${ }^{76}$ As also mentioned in other studies, expression of chitinase gene in Nicotina sylvestris did not increase resistance to Cercospora nicotiana; ${ }^{77}$ neither expression of PGIP2 gene in wheat reduced the symptoms of Claviceps 19 purpurea; ${ }^{78}$ additionally expression of $\beta-1,3$ glucanase in alfalfa did not decrease the severity of chitin containing fungus. ${ }^{79}$ and a rice basic chitinase ( $\mathrm{RCH} 10$ Moreover, identification of potentially useful genes to be engineered in plants is another huge task which greatly varies amongst plant species. Transformation and genome editing face additional challenges of extremely low transformation frequency and very few cell lines have the appropriate acquired the desired genetic expression..$^{80}$

\section{COMMERCIAL DEVELOPMENT}

Regardless of the victory of specific plant secondary metabolites substances as drugs, their restricted accessibility and challenging synthesis often make them only leads and not candidate drugs for scientists and pharmaceutical companies in the quest for new therapeutic hits. ${ }^{81}$ With the increasing economic significance of secondary plant metabolites, enormous amount of efforts are put into research to understand and 
Table 1: Genetic modifications done in biosynthetic pathway of medicinal plants to enhance secondary metabolite production or to reduce degrading pathways.

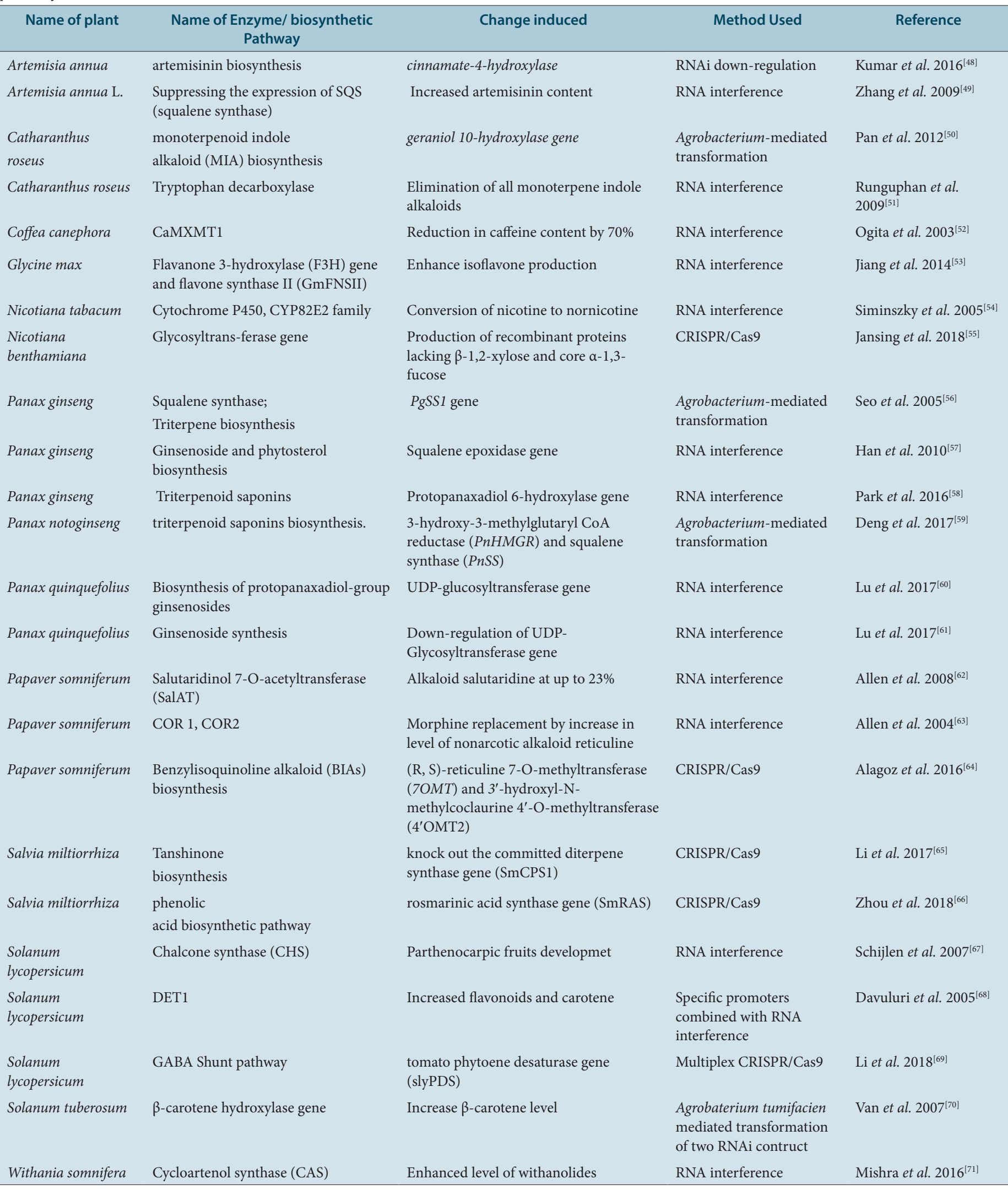


Sinha, et al:: Secondary Metabolism Enhancement through Gene Level Modification in Therapeutic Plants

\section{Genomics}

(deals with genes present in a medicinal plant)

$\downarrow$ Transcription

Transcriptomics

(all the transcribed mRNA present at a time in a medicinal plant)

$\downarrow$ Translation

$\downarrow \begin{aligned} & \text { Post-translation } \\ & \text { modification }\end{aligned}$

Proteomics

(all proteins present at a time in a medicinal plant)

$\downarrow$ Enzyme Activity

Metabolomics

(deals with all biosynthetic pathways of metabolites present at a time in a medicinal plant)

Figure 5: Relationship between Genomics and Metabolomics.

manipulate the biosynthetic pathways using various chemical, physiological and biotechnological methods. ${ }^{82}$ To improve productivity and evaluate improvement in secondary metabolites production from plant system, a holistic approach needs to be adopted, with more advanced technologies. These new technological developments can provide enhanced opportunities for continued usefulness of medicinally important plants to be developed as a renewable source of medicinal compounds. With increased intensification of efforts in the field of biotechnology, successful commercial methods of specific and valuable plant chemicals production can be developed. ${ }^{83}$

Bioactive compounds are produced either directly or indirectly by a considerable number of pharmaceutical industries at a larger scale. With evolving techniques of molecular biology, studies on production of transgenic cultures and subsequent effect on expression and regulation of biosynthetic pathways, is stride in the direction of making cell cultures by and significant more applicable for commercial production of secondary metabolites. ${ }^{84,85}$ A combined effort of metabolic engineering and bioinformatics techniques can solve the problem of limited availability of bioactive compounds from medicinal plants. By combining plant cell culture technologies of plant biotechnology with metabolic engineering, transformed cells in reactors under controlled conditions can be a replacement of field-grown plants, for plant secondary metabolite production. ${ }^{86,87}$

Another improvement towards the development of new fermentation processes for industrialized production of natural plant products is based on metabolic engineering of microorganisms for the desired biosynthetic pathway. This method has several advantages like its economic feasibility, environmentally friendly, low energy requirements and reduced waste emissions. ${ }^{88}$ In the extension of the stated method, flavonoid production has been enhanced by systematically fine-tuning the central metabolic pathways based on a CRISPR gene editing system in Escherichia coli and thereby efficiently channeling carbon flux toward malonyl-CoA without significantly altering the final biomass accumulation. ${ }^{89}$ Synthetic bioengineering of Rhodotorula glutinis phenylalanine/ tyrosine ammonia lyase has also been developed to produce a phenylpropanoid acid precursor in Escherichia coli, to improve trans-cinnamic acid and $p$-coumaric acid production..$^{0}$

\section{FUTURE PROSPECTS}

With the addition of sophisticated bioinformatics and metabolomic tools based on biochemical, genetic, environmental and developmental parameters, it will offer improvement in understanding of primary and secondary metabolic pathways in medicinal plants. Moreover, with increasing number of sequenced and annotated plant genomes, candidate gene(s) can be easily traced, which are associated with our desired trait or feature.

Medicinal plants with desired amount and composition of specific secondary metabolites can be developed with the amalgamation of traditional plant breeding techniques and tissue culture along with with genetic and metabolic engineering methods. The transgenic plants are always addressed with reservations during selection. Therefore, the production of genetically improved medicinal plants without foreign gene(s) is now an indispensable constraint for commercial development. When generating genetically improved plants, metabolic engineering methods such as RNAi induced gene silencing, cisgenesis, or intragenesis show more significant commercial potential and approval. Of late, it has been established that by using CRISPR-Cas effector, DNA can be edited/ engineered in both mammalian and plants cells. This advancement now unlocks new prospect of metabolic engineering and functional genomics, predominantly at RNA level.

The potential of pharmacologically active secondary plant metabolites is often restricted by low yield and availability of the producing plant. To add to the woes, chemical synthesis of these complex compounds is often too expensive and also do not provide with the correct structure or chirality of the compound. Plant cell culture offers an efficient strategy to overcome these limitations. Additionally, plant tissue culture proves to be an efficient method for continuous production of secondary metabolites and engineered molecules from medicinally important plants. Methods of gene editing can further improve the technique.

\section{CONCLUSION}

Metabolic engineering procedures reported in recent experiments illustrate that when the rate-limiting steps of the biosynthetic pathway are identified and the respective genes are cloned, the accurate regulation towards overproduction of desired medicinal product is feasible commercially. With expansion of boundaries of metabolic engineering it might also be possible to fabricate array of new compounds in plants or their respective tissue cultures by introducing foreign genes coding for enzymes, which can convert existing compounds to newer products and open means for more unique pathways.

\section{ACKNOWLEDGEMENT}

Authors are thankful to the anonymous reviewers for their careful reading of the manuscript and for providing insightful suggestions.

\section{CONFLICT OF INTEREST}

There are no conflicts of interest.

\section{ABBREVIATIONS}

4'OMT2: $\quad$ 3'-hydroxyl-N-methylcoclaurine $\quad$ 4'-O-methyltransferase; 7OMT: R/S-reticuline 7-O-methyltransferase; CRISPR-Cas9: Clustered Regularly Interspaced Short Palindromic; DNA: Deoxyribonucleic Acid; RNA: Ribonucleic Acid; slyPDS: Tomato phytoene desaturase gene; SmCPS1: Committed diterpene synthase gene; SmRAS: rosmarinic acid synthase gene. 


\section{REFERENCES}

1. Sangwan NS, Jadaun JS, Tripathi S, Mishra B, Narnoliya LK, Sangwan RS. Plant Metabolic Engineering. In: Omics Technologies and Bio-Engineering. Elsevier. 2018;143-75.

2. Kaushik P, Andújar I, Vilanova S, Plazas M, Gramazio P, Herraiz FJ, et al. Breeding Vegetables with Increased Content in Bioactive Phenolic Acids. Molecules. 2015;20(10):18464-81.

3. Kennedy DO, Wightman EL. Herbal extracts and phytochemicals: Plant secondary metabolites and the enhancement of human brain function. Advances Nutrition. 2011;2(1):32-50

4. Chen MS. Inducible direct plant defense against insect herbivores: A Review. Insect Sci. 2008;15(2):101-14.

5. Kaushik P, Gramazio P, Vilanova S, Raigón MD, Prohens J, Plazas M. Phenolics content, fruit flesh colour and browning in cultivated eggplant, wild relatives and interspecific hybrids and implications for fruit quality breeding. Food Res Int. 2017;102:392-401.

6. Pyne ME, Narcross L, Martin VJJ. Engineering Plant Secondary Metabolism in Microbial Systems1[OPEN]. Plant Physiol. 2019;179(3):844-61.

7. Yang L, Wen KS, Ruan X, Zhao YX, Wei F, Wang Q. Response of Plant Secondary Metabolites to Environmental Factors. Molecules. 2018;23(4):E762.

8. Hussein RA, El-Anssary AA. Plants Secondary Metabolites: The Key Drivers of the Pharmacological Actions of Medicinal Plants. Herbal Medicine. 2018.

9. Yuan H, Ma Q, Ye L, Piao G. The Traditional Medicine and Modern Medicine from Natural Products. Molecules. 2016;21(5):559.

10. Springob K, Kutchan TM. Introduction to the Different Classes of Natural Products Plant-derived Natural Products: Synthesis, Function and Application. New York, NY: Springer US. 2009;3-50.

11. Cordell GA. Natural products in drug discovery-creating a new vision. Phyto Rev. 2002;1(3):261-73.

12. Ekor M. The growing use of herbal medicines: Issues relating to adverse reactions and challenges in monitoring safety. Front Pharmacol. 2014;4:177.

13. Nasri H, Baradaran A, Shirzad H, Rafieian-Kopaei M. New Concepts in Nutraceuticals as Alternative for Pharmaceuticals. Int J Prev Med. 2014;5(12):1487-99.

14. Wachtel-Galor S, Benzie IFF. Herbal Medicine: An Introduction to Its History, Usage, Regulation, Current Trends and Research Needs. Herbal Medicine: Biomolecular and Clinical Aspects. Boca Raton (FL): CRC Press/Taylor and Francis. 2011.

15. Kaushik P. Standardisation of an Agroinfiltration Protocol for Eggplant Fruits and Proving its Usefulness by Over-expressing the SmHQT Gene. Preprints. 2019.

16. Pickens LB, Tang Y, Chooi YH. Metabolic Engineering for the Production of Natural Products. Annu Rev Chem Biomol Eng. 2011;2:211-36.

17. Fu R, Martin C, Zhang Y. Next-Generation Plant Metabolic Engineering, Inspired by an Ancient Chinese Irrigation System. Mol Plant. 2018;11(1):47-57.

18. Alper HS, Avalos JL. Metabolic pathway engineering. Synth Syst Biotechnol. 2018;3(1):1-2.

19. Römer S, Lübeck J, Kauder F, Steiger S, Adomat C, Sandmann G. Genetic engineering of a zeaxanthin-rich potato by antisense inactivation and co-suppression of carotenoid epoxidation. Metab Eng. 2002;4(4):263-72.

20. Sanchez S, Demain AL. Metabolic regulation and overproduction of primary metabolites. Microb Biotechnol. 2008;1(4):283-319.

21. Thirugnanasambantham $P$, Senthil $K$. In vitro and omics technologies opens a new avenue for deciphering withanolide metabolism in Withania somnifera. Int J Pharm Pharm Sci. 2016;8(7):17-26.

22. Health NRC (US) C on I and AUE of GEF on $\mathrm{H}$. Methods and Mechanisms for Genetic Manipulation of Plants, Animals and Microorganisms. National Academies Press (US). 2004

23. Kaushik P. Application of Conventional, Biotechnological and Genomics Approaches for Eggplant (Solanum melongen L). Breeding Focus Bioactive Phenolics. 2019

24. Hwang HH, Yu M, Lai EM. Agrobacterium-Mediated Plant Transformation: Biology and Applications. The Arabidopsis Book. 2017;e0186.

25. Ahn YK, Yoon MK, Jeon JS. Development of an efficient Agrobacterium-mediated transformation system and production of herbicide-resistant transgenic plants in garlic (Allium sativum L.). Mol Cells. 2013;36(2):158-62.

26. Saini DK, Kaushik P. Visiting eggplant from a biotechnological perspective: A review. Sci Hort. 2019;253:327-40.

27. Pistelli L, Giovannini A, Ruffoni B, Bertoli A, Pistelli L. Hairy Root Cultures for Secondary Metabolites Production. Adv Exp Med Biol. 2010;698:167-84.

28. Eamens A, Wang MB, Smith NA, Waterhouse PM. RNA Silencing in Plants: Yesterday, Today and Tomorrow. Plant Physiol. 2008;147(2):456-68.

29. Kooter JM, Matzke MA, Meyer P. Listening to the silent genes: Transgene silencing, gene regulation and pathogen control. Trends Plant Sci. 1999;4(9):340 7.

30. Fire A. RNA-triggered gene silencing. Trends Genet. 1999;15(9):358-63.

31. Ossowski S, Schwab R, Weigel D. Gene silencing in plants using artificial microRNAs and other small RNAs. Plant J. 2008;53(4):674-690.
32. Hussain MdS, Fareed S, Ansari S, Rahman MdA, Ahmad IZ, Saeed M. Current approaches toward production of secondary plant metabolites. J Pharm Bioallied Sci. 2012;4(1):10-20.

33. Dhar N, Razdan S, Rana S, Bhat WW, Vishwakarma R, Lattoo SK. A Decade of Molecular Understanding of Withanolide Biosynthesis and in vitro Studies in Withania somnifera (L.) Dunal: Prospects and Perspectives for Pathway Engineering. Front Plant Sci. 2015;6:1031.

34. Wijekoon CP, Facchini PJ. Systematic knockdown of morphine pathway enzymes in opium poppy using virus-induced gene silencing. Plant J. 2012;69(6):1052-63.

35. Agrawal N, Dasaradhi PVN, Mohmmed A, Malhotra P, Bhatnagar RK, Mukherjee SK. RNA interference: Biology, mechanism and applications. Microbiol Mol Biol R. 2003;67(4):657-85.

36. Wilson R, Doudna JA. Molecular mechanisms of RNA interference. Annu Rev Biophys. 2013;42:217-39.

37. Leuschner PJF, Ameres SL, Kueng S, Martinez J. Cleavage of the siRNA passenger strand during RISC assembly in human cells. EMBO Rep. 2006;7(3):314-20.

38. Loureiro A, DaSilva GJ. CRISPR-Cas: Converting A Bacterial Defence Mechanism into A State-of-the-Art Genetic Manipulation Tool. Antibiotics. 2019;8(1):18.

39. Hille F, Charpentier E. CRISPR-Cas: Biology, mechanisms and relevance. Philos Trans R Soc Lond B Biol Sci. 2016;371(1707):20150496.

40. Rodríguez-Rodríguez DR, Ramírez-Solís R, Garza-Elizondo MA, DeLourdes Garza-RM, Barrera-Saldaña HA. Genome editing: A perspective on the application of CRISPR/Cas9 to study human diseases (Review). Int J Mol Med. 2019;43(4):1559-74

41. Prykhozhij SV, Rajan V, Gaston D, Berman JN. CRISPR MultiTargeter: A Web Tool to Find Common and Unique CRISPR Single Guide RNA Targets in a Set of Similar Sequences. PLoS One. 2015;10(3):e0119372.

42. Naito Y, Hino K, Bono H, Ui-Tei K. CRISPR direct: Software for designing CRISPR/ Cas guide RNA with reduced off-target sites. Bioinformatics. 2015;31(7):1120-3

43. Park J, Bae S, Kim JS. Cas-Designer: A web-based tool for choice of CRISPRCas9 target sites. Bioinformatics. 2015;31(24):4014-6.

44. Jaganathan D, Ramasamy K, Sellamuthu G, Jayabalan S, Venkataraman G. CRISPR for Crop Improvement: An Update Review. Front Plant Sci. 2018;9.

45. Minkenberg B, Zhang J, Xie K, Yang Y. CRISPR-PLANT v2: An online resource for highly specific guide RNA spacers based on improved off-target analysis. Plant Biotechnol J. 2019;17(1):5-8.

46. Luo Y, Li BZ, Liu D, Zhang L, Chen Y, Jia B, et al. Engineered Biosynthesis of Natural Products in Heterologous Hosts. Chem Soc Rev. 2015;44(15):5265-90.

47. Borrelli VMG, Brambilla V, Rogowsky P, Marocco A, Lanubile A. The Enhancement of Plant Disease Resistance Using CRISPR/Cas9 Technology. Front Plant Sci. 2018;9.

48. Kumar R, Vashisth D, Misra A, Akhtar MQ, Jalil SU, Shanker K, et al. RNAi downregulation of cinnamate-4-hydroxylase increases artemisinin biosynthesis in Artemisia annua. Sci Rep. 2016;6:26458.

49. Zhang L, Jing F, Li F, Li M, Wang Y, Wang G, et al. Development of transgenic Artemisia annua (Chinese wormwood) plants with an enhanced content of artemisinin, an effective anti-malarial drug, by hairpin-RNA-mediated gene silencing. Biotechnol Appl Biochem. 2009;52(3):199-207.

50. Pan Q, Wang Q, Yuan F, Xing S, Zhao J, ChoiYH, et al. Overexpression of ORCA3 and $\mathrm{G} 10 \mathrm{H}$ in Catharanthus roseus Plants Regulated Alkaloid Biosynthesis and Metabolism Revealed by NMR-Metabolomics. PLoS One. 2012;7(8):e43038.

51. Runguphan W, Maresh JJ, O'Connor SE. Silencing of tryptamine biosynthesis for production of nonnatural alkaloids in plant culture. PNAS. 2009;106(33):136738

52. Ogita S, Uefuji H, YamaguchiY, Koizumi N, Sano H. RNA interference: Producing decaffeinated coffee plants. Nature. 2003;423(6942):823.

53. Jiang $Y, H u Y$, Wang $B$, Wu T. Bivalent RNA interference to increase isoflavone biosynthesis in soybean (Glycine max). Braz Arch of Biol Technol. 2014;57(2):16370

54. Siminszky B, Gavilano L, Bowen SW, Dewey RE. Conversion of nicotine to nornicotine in Nicotiana tabacum is mediated by CYP82E4, a cytochrome P450 monooxygenase. Proc Natl Acad Sci USA. 2005;102(41):14919-24.

55. Jansing J, Sack M, Augustine SM, Fischer R, Bortesi L. CRISPR/Cas9-mediated knockout of six glycosyltransferase genes in Nicotiana benthamiana for the production of recombinant proteins lacking $\beta-1,2$-xylose and core $\alpha-1,3$-fucose. Plant Biotechnol J 02. 2019;17(2):350-61.

56. Seo JW, Jeong JH, Shin CG, Lo SC, Han SS, Yu KW, et al. Overexpression of squalene synthase in Eleutherococcus senticosus increases phytosterol and triterpene accumulation. Phytochemistry. 2005;66(8):869-77.

57. Han JY, In JG, Kwon YS, ChoiYE. Regulation of ginsenoside and phytosterol biosynthesis by RNA interferences of squalene epoxidase gene in Panax ginseng. Phytochemistry. 2009;71(1):36-46.

58. Park SB, Chun JH, Ban YW, Han JY, Choi YE. Alteration of Panax ginseng saponin composition by overexpression and RNA interference of the protopanaxadiol 6-hydroxylase gene (CYP716A53v2). J Ginseng Res. 2016;40(1):47-54

59. Deng B, Zhang P, Ge F, Liu DQ, Chen CY. Enhancement of triterpenoid saponins biosynthesis in Panax notoginseng cells by co-overexpressions of 3-hydroxy3-methylglutaryl CoA reductase and squalene synthase genes. Biochem Eng 
J. 2017;122:38-46.

60. Lu C, Zhao SJ, Wang XS. Functional regulation of a UDP-glucosyltransferase gene (Pq3-O-UGT1) by RNA interference and overexpression in Panax quinquefolius. Plant Cell Tiss Org. 2017;129(3):445-56.

61. Lu C, Zhao S, Wei G, Zhao H, Qu Q. Functional regulation of ginsenoside biosynthesis by RNA interferences of a UDP-glycosyltransferase gene in Panax ginseng and Panax quinquefolius. Plant Physiol Bioch. 2017;111:67-76.

62. Allen RS, Miller JAC, Chitty JA, Fist AJ, Gerlach WL, Larkin PJ. Metabolic engineering of morphinan alkaloids by over-expression and RNAi suppression of salutaridinol 7-O-acetyltransferase in opium poppy. Plant Biotechnol J. 2008;6(1):22-30

63. Allen RS, Millgate AG, Chitty JA, Thisleton J, Miller JAC, Fist AJ, et al. RNAimediated replacement of morphine with the nonnarcotic alkaloid reticuline in opium poppy. Nat Biotechnol. 2005;22(12):1559-66.

64. AlagozY, GurkokT, Zhang B, UnverT. Manipulating the Biosynthesis of Bioactive Compound Alkaloids for Next-Generation Metabolic Engineering in Opium Poppy Using CRISPR-Cas 9 Genome Editing Technology. Sci Rep. 2016;6:30910.

65. Li B, Cui G, Shen G, Zhan Z, Huang L, Chen J, et al. Targeted mutagenesis in the medicinal plant Salvia miltiorrhiza. Sci Rep. 2017;7:43320.

66. Zhou J, Du G, Chen J. Novel fermentation processes for manufacturing plant natural products. Curr Opin Biotechnol. 2014;25:17-23.

67. Schijlen EGWM, DeVos CHR, Martens S, Jonker HH, Rosin FM, Molthoff JW, et al. RNA Interference Silencing of Chalcone Synthase, the First Step in the Flavonoid Biosynthesis Pathway, Leads to Parthenocarpic Tomato Fruits. Plant Physiol. 2007;144(3):1520-30.

68. Davuluri GR, Tuinen AV, Fraser PD, Manfredonia A, Newman R, Burgess D, et al. Fruit-specific RNAi-mediated suppression of DET1 enhances carotenoid and flavonoid content in tomatoes. Nat Biotechnol. 2005;23(7):890-5.

69. Li R, Li X, Fu D, Zhu B, Tian H, et al. Multiplexed CRISPR/Cas9-mediated metabolic engineering of $\gamma$-aminobutyric acid levels in Solanum lycopersicum. Plant Biotechnol J. 2018;16(2):415-27.

70. Eck JV, Conlin B, Garvin DF, Mason H, Navarre DA, Brown CR. Enhancing betacarotene content in potato by rnai-mediated silencing of the beta-carotene hydroxylase gene. Amer J of Potato Res. 2007;84(4):331.

71. Mishra S, Bansal S, Sangwan RS, Sangwan NS. Genotype independent and efficient Agrobacterium-mediated genetic transformation of the medicinal plant Withania somnifera Dunal. J Plant Biochem Biotechnol. 2016;25(2):191-8.

72. Biosciences NRC (US) C on. Molecular Genetics and Genetic Engineering. National Academies Press (US). 1985.

73. Ma Y, Liu Y, Cheng J. Protein Secondary Structure Prediction Based on Data Partition and Semi-Random Subspace Method. Sci Rep. 2018;8(1):9856.

74. Rahman M, Shaheen T, Rahman M, Iqbal MA, Zafar Y. Bioinformatics: A Way Forward to Explore "Plant Omics." Bioinformatics. 2016.

75. Rahaman MdM, Chen D, Gillani Z, Klukas C, Chen M. Advanced phenotyping and phenotype data analysis for the study of plant growth and development.
Front Plant Sci. 2015;6:619.

76. Gelvin SB. Agrobacterium-Mediated Plant Transformation: The Biology behind the "Gene-Jockeying" Tool. Microbiol Mol Biol Rev. 2003;67(1):16-37.

77. Neuhaus JM, Ahl-Goy P, Hinz U, Flores S, Meins F. High-level expression of a tobacco chitinase gene in Nicotiana sylvestris. Susceptibility of transgenic plants to Cercospora nicotianae infection. Plant Mol Biol. 1991;16(1):141-51.

78. Volpi C, Raiola A, Janni M, Gordon A, O'Sullivan DM, Favaron F et al. Claviceps purpurea expressing polygalacturonases escaping PGIP inhibition fully infects PVPGIP2 wheat transgenic plants but its infection is delayed in wheat transgenic plants with increased level of pectin methyl esterification. Plant Physio Biochem. 2013;73:294-301.

79. Masoud SA, Zhu Q, Lamb C, Dixon RA. Constitutive expression of an inducible $\beta-1,3-$ glucanase in alfalfa reduces disease severity caused by the oomycete pathogen Phytophthora megasperma $f$. spmedicaginis, but does not reduce disease severity of chitin-containing fungi. Transgenic Res. 1996;5(5):313-23.

80. Ahmad N, Mukhtar Z. Genetic manipulations in crops: Challenges and opportunities. Genomics. 2017;109(5):494-505.

81. Mawalagedera SMUP, Callahan DL, Gaskett AC, Rønsted N, Symonds MRE. Combining Evolutionary Inference and Metabolomics to Identify Plants With Medicinal Potential. Front Ecol Evol. 2019;7:267.

82. Isah T. Secondary metabolism of pharmaceuticals in the plant in vitro cultures: strategies, approaches and limitations to achieving higher yield. Plant Cell Tiss Org. 2018;132(2):239-65.

83. Cardoso JC, DeOliveira MEB, DeCardoso FC, Cardoso JC, DeOliveira MEB, DeCardoso FC. Advances and challenges on the in vitro production of secondary metabolites from medicinal plants. Hortic Bras. 2019;37(2):124-32.

84. Cragg GM, Newman DJ. Natural Products: A Continuing Source of Novel Drug Leads. Biochim Biophys Acta. 2013;1830(6):3670-95

85. Yang L, Yang C, Li C, Zhao Q, Liu L, Fang $X$, et al. Recent advances in biosynthesis of bioactive compounds in traditional Chinese medicinal plants. Sci Bull. 2016;61:3-17.

86. Leonard E, Runguphan W, O'Connor S, Prather KJ. Opportunities in metabolic engineering to facilitate scalable alkaloid production. Nat Chem Biol. 2009;5(5):292-300.

87. Devi P, Kaushik P, Saini DK. QTLs identified for Biofortification Traits in Wheat: A Review. Preprints. 2019

88. Jarboe LR, Zhang X, Wang X, Moore JC, Shanmugam KT, Ingram LO. Metabolic Engineering for Production of Biorenewable Fuels and Chemicals: Contributions of Synthetic Biology. J Biomed Biotechnol. 2010;761042.

89. Wu J, Du G, Chen J, Zhou J. Enhancing flavonoid production by systematically tuning the central metabolic pathways based on a CRISPR interference system in Escherichia coli. Sci Rep. 2015;5:13477.

90. Liang JL, Guo L, Sun P, Jiang B, Lin J, Guo W, et al. A novel process for obtaining phenylpropanoic acid precursor using Escherichia coli with a constitutive expression system. Food Sci Biotechnol. 2016;25(3):795-801.

Article History: Submission Date : 04-09-2019; Revised Date : 05-10-2019; Acceptance Date : 24-10-2019.

Cite this article: Sinha S, Sandhu K, Bisht N, Naliwal T, Saini I, Kaushik P. Ascertaining the Paradigm of Secondary Metabolism Enhancement through Gene Level Modification in Therapeutic Plants. J Young Pharm. 2019;11(4):337-43. 